Supporting Information

\title{
Pragmatic Approach to Design Silicon Alloy Anode by the
}

\section{Equilibrium Method}

\author{
Nurzhan Umirov', Deok-Ho Seo ${ }^{\mathrm{a}}$, Hyang-Yeon Kim ${ }^{\mathrm{b}, *}$, Sung-Soo Kim ${ }^{\mathrm{a}, *}$
}

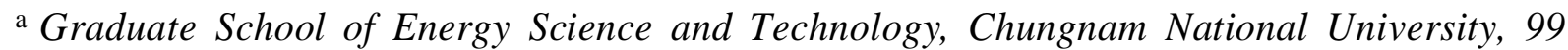
Daehak-ro, Yuseong-gu, Daejeon 34134, Republic of Korea.

${ }^{\mathrm{b}}$ Korea Institute of Industrial Technology, 6 Cheomdan-gwagiro 208, Buk-gu, Gwangju 61012, Republic of Korea.

*Corresponding authors:

H.-Y. Kim: Tel: +82-62-600-6390, Fax: +82-62-600-6149, e-mail: hy_kim@kitech.re.kr S.-S. Kim: Tel: +82-42-821-8613, Fax:+82-42-821-8839, e-mail: kimss@cnu.ac.kr. 


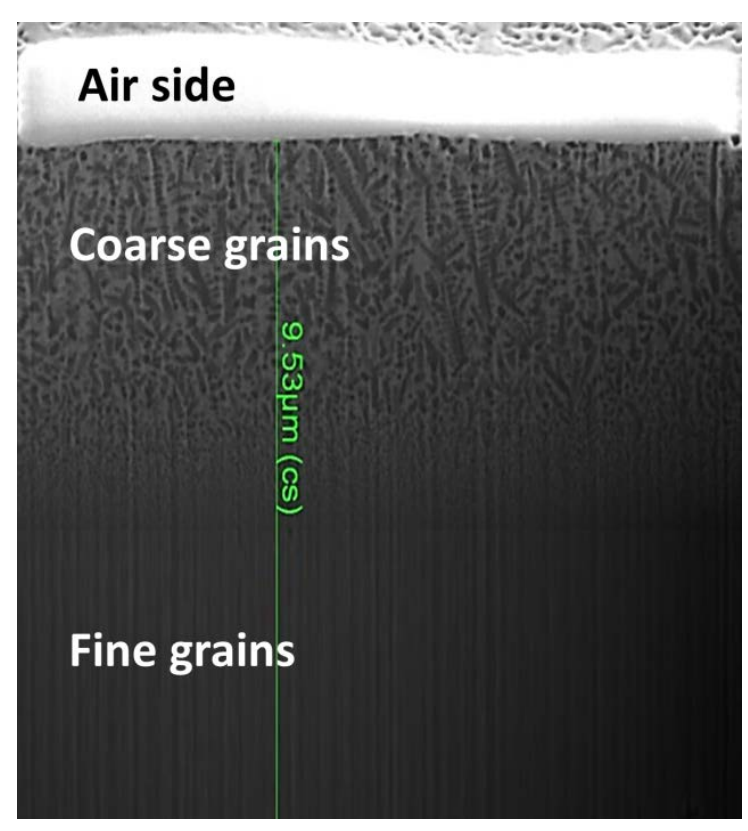

Figure S1. Cross-section TEM image of Si-alloy microstructure designed by non-equilibrium path.
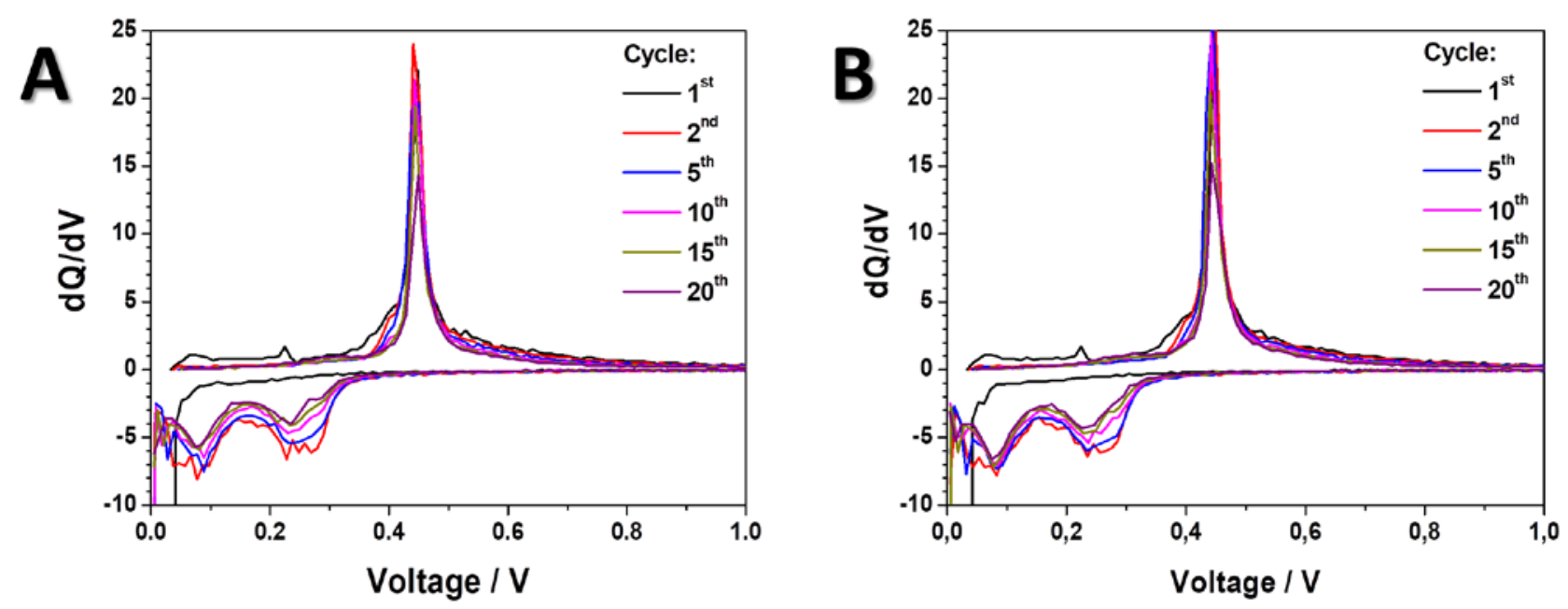

Figure S2. dQ/dV plots of SFA alloy (at $973 \mathrm{~K}$ ) with electrode density of a) 1.2 and b) $1.4 \mathrm{~g}$ $\mathrm{cm}^{-3}$. 


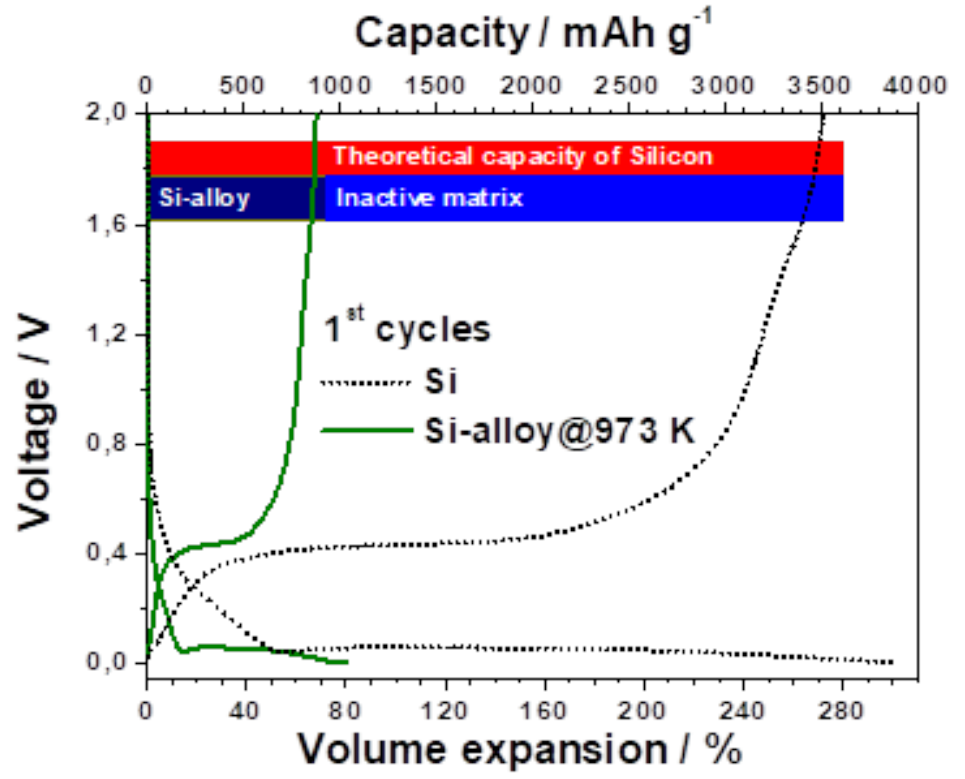

Figure S3. $1^{\text {st }}$ cycle charge/discharge profiles of Si and Si-alloy (at 973K).
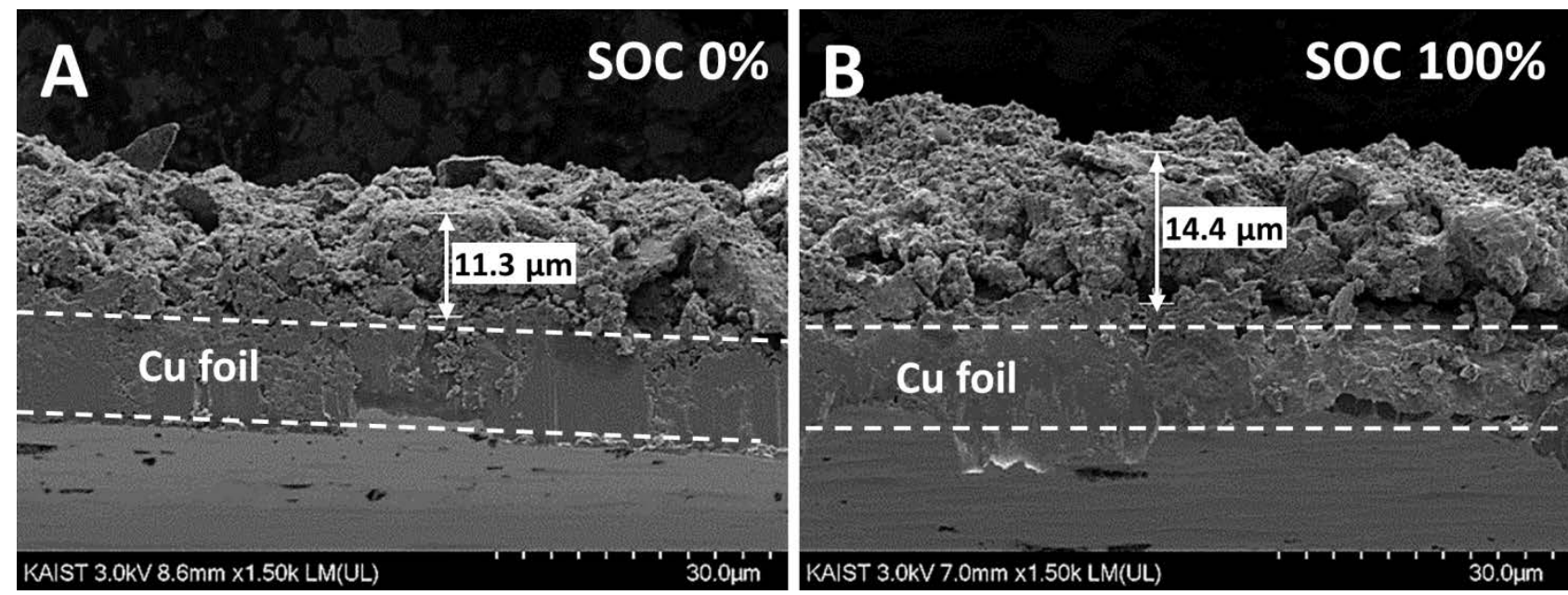

Figure S4. Cross-section images of Si-alloy (at 973K) electrode at SOC 0\% and SOC 100\%. 